\title{
Review Article \\ Bioactive Micronutrients in Coffee: Recent Analytical Approaches for Characterization and Quantification
}

\author{
Abdulmumin A. Nuhu \\ Department of Chemistry, Ahmadu Bello University, PMB 1069, Zaria, Kaduna 2222, Nigeria \\ Correspondence should be addressed to Abdulmumin A. Nuhu; aanuhu@yahoo.com
}

Received 22 September 2013; Accepted 7 November 2013; Published 22 January 2014

Academic Editors: D. Koya, T. Nurmi, and S. van Hemert

Copyright (C) 2014 Abdulmumin A. Nuhu. This is an open access article distributed under the Creative Commons Attribution License, which permits unrestricted use, distribution, and reproduction in any medium, provided the original work is properly cited.

Production of coffee beans is an important lifeline for the economy of several countries in Latin America, Africa, and Asia. The brew from this well sought for cash crop is readily consumed due to its good sensory qualities owing to the presence of many micronutrients. Some of these chemical compounds possess biological activities, including antiproliferative, antioxidant, and antimicrobial effects. Four representative groups of these micronutrients, namely, caffeine, chlorogenic acid, diterpenes, and trigonelline, play key roles in these bioactive effects of coffee. In order to guarantee the quality of coffee products and to protect consumer interest and safeguard their well-being, it is extremely important to employ sensitive and accurate analytical methods in the characterization and quantitative determination of these bioactive constituents. This review aims to present recent applications in this regard.

\section{Introduction}

Coffee is a popular beverage that is widely consumed around the world $[1,2]$. Since its introduction into Arabia from Ethiopia many centuries ago [3], its cultivation has continued to blossom in three regions of our globe, namely, Africa, Latin America and Asia, [4-6]. Coffee is often produced from the roasted beans of a great variety of coffee crops [7]. However, Coffea canephora and Coffea arabica are the two most economically important species $[8,9]$. It can now be found in both organic and conventional types [10]. Presently, the largest coffee bean producing region is Latin America [11], leading to an immense boost in the economy of the respective countries by bringing in the much needed foreign exchange. Unfortunately, market shocks, extreme weather conditions, and pests are an enormous challenge to this reality $[12,13]$. World prices of coffee beans vary reasonably with their geographical source, as this affects the physical presentation of these beans and their nutritive components, two factors that are important in determination of coffee quality [14-17].

There are many nutritive substances in coffee brews which vary with the types of techniques employed in brewing processes [18]. Coffee contains mineral ingredients such as $\mathrm{Ca}, \mathrm{K}$, $\mathrm{Fe}, \mathrm{P}, \mathrm{Ni}, \mathrm{Mg}$, and $\mathrm{Cr}$ [19], polyphenols, caffeine, melanoidins, and carbohydrates $[20,21]$ among others. Since the variability of these chemical constituents affects price of coffee commodities by determining their qualities, there must be sensitive, precise, and accurate analytical means for their determination. It is, therefore, the aim of this paper to present a review on the recent analytical methods that have been applied to the characterization and quantification of four important bioactive constituents in coffee: caffeine, chlorogenic acid, diterpenes, and trigonelline.

\section{Bioactive Compounds of Coffee}

Coffee is rich in many bioactive substances and its consumption has been associated with many beneficial effects [22]. These include, but not limited to, reduced risk of hepatocellular carcinoma [23], antiproliferative effect against some human cancer cell lines [24], therapeutic potential against Alzheimer's disease [25], and antioxidant capacity through modulation of Nrf2 nuclear translocation [26].

2.1. Caffeine. Caffeine $\left(\mathrm{C}_{8} \mathrm{H}_{10} \mathrm{~N}_{4} \mathrm{O}_{2}\right)$, an alkaloid that is chemically known as 1,3,7-trimethylxanthine (or 1,3,7-trimethyl-1H-purine-2, $6(3 \mathrm{H}, 7 \mathrm{H})$-dione), is among the most commonly consumed stimulants worldwide $[27,28]$. It 
<smiles>Cn1c(=O)c2c(ncn2C)n(C)c1=O</smiles>

FIGURE 1: Chemical structure of caffeine.

contains two fused rings (Figure 1) that are related to purines [29]. Caffeine is found in many natural and processed products. Examples of these sources include green tea [30, 31], mate tea [32, 33], chocolate [34], and caffeinated beverages and energy drinks [35-37]. C. arabica [38] and Robusta coffee (C. canephora var. Robusta) [39] also contain this micronutrient.

Consumption of caffeine has shown many positive effects in various human and animal experimentations. At a dose of $6 \mathrm{mgKg}^{-1}$ body mass, it was found to exhibit ergogenic effect, the ability to increase physical exercise without a concomitant increase in effort sensation, in sedentary men [40]. Its stimulatory activity was also tested, with some promising results, in persons with Parkinson's disease, where it can be used to manage both motor and nonmotor symptoms [41]. In a mouse model, crude caffeine was found to reduce the accumulation of $\beta$-amyloid peptides, a characteristic feature in patients suffering from Parkinson's disease [42]. Investigations have revealed that crude caffeine did possess hydrophilic antioxidant activity (145 $\mu \mathrm{mol}$ Trolox equivalent (TE)/g) and lipophilic antioxidant activity $(66 \mu \mathrm{mol} \mathrm{TE} / \mathrm{g})$, and its administration has led to the inhibition of cyclooxygenase-2 enzyme better than aspirin [43].

Some of the adverse effects of high doses of caffeine include decrease tonus of the lower esophageal sphincter muscle, overstimulation of central nervous system, intrauterine growth retardation, and higher risk of miscarriage [44]. Withdrawal from caffeine ingestion may present with lower mental alertness, diminished performance, and over sleepiness [45].

2.2. Chlorogenic Acid. Chlorogenic acid (CGA) (Figure 2), which has nothing to do with chlorine, is an ester that is formed from the reaction of caffeic acid with L-quinic acid; hence the name 5-caffeoylquinic acid (5-CQA) [46, 47]. It is a polyphenolic compound that is abundant in many plants [48]. It is present in tobacco leaves [49], mulberry tree [50], and coffee beans [51]. It is found to be responsible for the astringent taste of coffee brews $[52,53]$. Many positive effects have been attributed to CGA. For instance, its hypolipidemic effect has led to weight reduction in experimental mice [54, 55]. The antioxidant activities of this phytochemical were exhibited against ischemia-reperfusion injury [56] and in the protection against oxidative damage of macromolecules such as DNA, lipids, and proteins [57]. When administered to mice under scopolamine-induced amnesia, CGA has shown neuroprotective function via the inhibition of acetyl cholinesterase [58].

Different microbial entities are susceptible to CGA's antimicrobial activities. With respect to viruses, CGA has shown

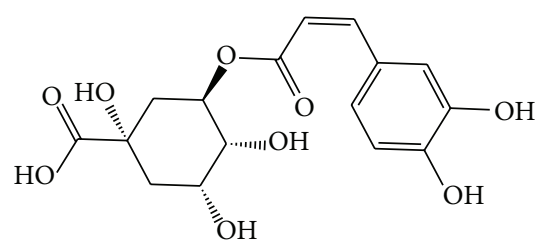

Figure 2: Chemical structure of chlorogenic acid.

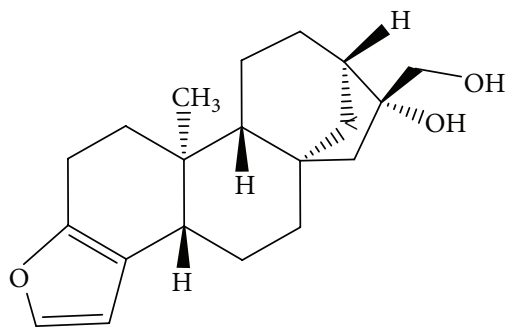

FIgURE 3: Chemical structure of the diterpene cafestol.

antihepatitis B virus potency in a duckling model [59] and potential anti-H1N1 influenza virus [60]. CGA analogs that showed appreciable anti-HIV activities have been synthesized [61]. CGA is not only active against viral particles, but it has also antibacterial and antifungal functions. At minimum inhibitory concentrations (MIC) of $20-80 \mu \mathrm{g} / \mathrm{mL}$, the growth of all bacterial pathogens tested was inhibited by CGA [62]. It is argued that the high resistance of immature peach fruits to the brown rot fungus, Monilinia laxa, is due to their high contents of CGA [63].

2.3. Diterpenes. Diterpenes are a group of terpenoids commonly found as secondary metabolites in terrestrial and marine organisms [64]. They often occur in a C-20 backbone where isoprene units combine in different forms to give an array of diterpenes such as abietane [65], cembrane [66], guanacastepene A [67], quinonoid [68], jatropha [69], and cafestol and kahweol [70] types. These and several others may be found in coffee [71], tea [72], and Salvia spp. [73]. Some types have been isolated from the fungus Trichoderma longibrachiatum [74] and from sponge family [75].

Diterpenes have displayed several types of bioactivities via different mechanisms. A diterpene alkaloid isolated from the Caribbean sponge Agelas citrina has shown antifungal function [76]. Experiment with oridonin type has demonstrated its antiproliferative effect against leukemia-derived Jurkat cells [77]. Abietane type was cytotoxic to human pancreatic cancer cell line MIA PaCa-2 [78]. Antioxidant function is found in Salvia officinalis [79], and an isolate of the Brazilian alga Dictyota menstrualis has indicated anti-HIV potential of this phytochemical [80]. Antimicrobial activities are found in a recent review [81]. Some diterpenes are toxic to insects [82] and to embryos of medaka, Japanese rice fish [83]. Structure of cafestol is given in Figure 3.

2.4. Trigonelline. Trigonelline (TRG) (Figure 4) is a nitrogenous compound, a pyridine alkaloid that is derived from the methylation of the nitrogen atom of nicotinic acid (niacin); 
<smiles>C[n+]1cccc(C(=O)[O-])c1</smiles>

FIgURE 4: Chemical structure of trigonelline.

hence the name $\mathrm{N}$-methyl nicotinic acid [84-86]. TRG is found in pumpkin seeds [87], mangrove legumes [88], Moringa oleifera tree [89], and coffee [90,91]. It is used as roasting level discriminator in both Arabica and Robusta coffees [92].

TRG has a proven antidiabetic effect; its administration to model rats suffering from diabetes mellitus has resulted in reduced blood glucose levels in oral glucose tolerance test [93]. It has also shown beneficial effects in rats displaying peripheral neuropathy, a condition for which there is no effective drug for its treatment [94]. Its function as an inhibitor of Nrf2 gene transcription has caused pancreatic cancer cells to be more susceptible to cell death through apoptosis [95]. At an MIC of $0.8 \mathrm{mg} / \mathrm{mL}$, TRG content of C. canephora extracts has correlated positively with reduction in biofilm formation via bacteriostatic action on Streptococcus mutans [96].

\section{Extraction Methods for Bioactive Micronutrients of Coffee}

Extraction and preconcentration procedures may be necessary for any good and sensitive characterization and determination of analytes, especially when these are present in very low concentrations. Many traditional and conventional methods have been employed in the extraction of bioactive micronutrients of coffee preparatory to their analysis.

3.1. Solid-Liquid Extraction. Different types of coffee brewing techniques have profound influence on the types and amounts of chemical compounds in coffee [18]. These techniques, all of which are based on solid-liquid extraction (SLE), include Boiled, Morcha Pot, French press, Turkish, Plunger, and Espresso types [97, 98]. On comparison, Turkish style and French press provided the highest amounts of kahweol and cafestol compared to others [71]. In SLE, water is often the solvent for extraction, which is beneficial to polar and water-soluble analytes [70]. For analytical determinations, extraction can be carried out in other solvents but may be reconstituted in water before further analysis [89]. Bi et al. [99], however, found that a mixture of ethanol and water (50/50, v/v) was most effective for removal of caffeine from coffee waste. During a 90 min extraction, $60 \%$ methanol and a solvent/solid ratio of $40 \mathrm{~mL} / \mathrm{g}$ spent coffee grounds provided the best conditions for obtaining extract with high phenolic compounds, including CGA [100]. Because the main discriminator in these SLE methods is polarity, it leads to limited selectivity in extraction; when caffeine was analyzed in roasted coffee ground, not only caffeine was extracted with the SLE procedure [101]. This method of extraction may, therefore, present interference problems during instrumental analysis.
Other conditions that define the performance of SLE procedures are the effect of temperature and duration of extraction $[92,102]$. As a result of different temperature sensitivities of the complex mixture of constituents in coffee, it is difficult to satisfy the temperature needs of individual analytes in a single-extraction system. In an attempt to eliminate this challenge, a double-extraction method was described which accommodated the extraction of both thermolabile CGA and thermostable caffeine, with high recoveries [20]. In this system, one batch is fed into selected stages at mild temperature and pressure while another is fed into remaining stages at higher temperature and pressure, and $50 \%$ of extracts from each stream are mixed and lyophilized. Apart from being cumbersome, multistep SLE may lead to loss of some analytes. It was recently found that proprietary ethanol singlestep extraction resulted in higher content of caffeine than multistep procedures [103].

3.2. Liquid-Liquid Extraction and Solid-Phase Extraction. Liquid-liquid extraction (LLE) is one of the most widely used traditional sample preparation techniques [104]. The disparity in solubility of an analyte in two immiscible solvents is harnessed for its extraction. For the extraction of the four bioactive constituents of coffee, LLE can be practiced by extracting these analytes from aqueous medium to an organic one. However, because each of these constituents has, at least, a moderate solubility in water, application of LLE in this regard is limited. In one example, caffeine was extracted from water into dichloromethane, while CGA remained in the residual aqueous solution [105]. To solubilize a polar analyte in an organic solvent during an LLE procedure, especially when gas chromatographic analysis is intended, it is sometimes necessary to add ionic surfactants in the extraction medium $[106,107]$.

Solid-phase extraction (SPE) utilizes the sorptive capacity of a stationary sorbent in SPE cartridge in order to extract analytes. It starts by conditioning the cartridge, after which the sample is run through, then dried, and finally eluted using a suitable solvent $[108,109]$. Recently, Caprioli et al. [110] have explained the application of SPE for the extraction of CGA in Arabica and Robusta coffees using Strata-X cartridge. Low temperatures and methanol as extraction solvent resulted in the most efficient extraction of CGA.

Both LLE and SPE applications are dwarfed by being multistep and environmentally unfriendly due to large solvent volumes involved, especially with regard to LLE.

\subsection{Microwave-Assisted and Ultrasound-Assisted Extractions.} Microwave-assisted extraction (MAE) is a solvent reduction extraction method that uses electromagnetic energy to assist (enhance) extraction of analytes. Microwave interacts with matter in a special way that causes instantaneous heating, thus facilitating desorption of analytes from their matrices and improving mass transfer rate [111, 112]. Compared to conventional solvent extraction, MAE is faster and involves minimal use of solvent. In just under $40 \mathrm{~s}$, maximum phenolic content was obtained from spent filter coffee under the influence of low concentrated ethanol [113]. Hongcheng et al. 
[114] have developed a fast MAE method for the simultaneous extraction of TRG, caffeine and nicotinic acid from coffee using a pressure of 200 psi. Other conditions that can affect this procedure include temperature and wattage. At the temperature of $50^{\circ} \mathrm{C}$ and wattage of $800 \mathrm{w}, \mathrm{CGA}$ - and caffeinerich extracts were prepared from coffee beans [115].

Another assisted extraction procedure is ultrasoundassisted extraction (UAE), a procedure that uses sound frequency to agitate extraction medium and speed up contact between solvent and matrix. It has found a number of applications in the extraction of phytochemicals $[50,116]$. The energy burst from UAE equipment causes thermal heating that reduces extraction time. Wang et al. [117] have found that quantity of caffeine extracted from coffee reached saturation in only $15 \mathrm{~s}$ and augmented positively with increase in temperature at an operating frequency of $28 \mathrm{kHz}$. UAE was successfully applied to the determination of TRG in coffee powder and instant coffee with excellent recoveries [118].

Some of the demerits of MAE and UAE include the difficulty in selecting appropriate extraction conditions (including type of solvent, pressure, and frequency) that would not cause excessive heating and lead to degradation of some analytes, necessity of clean-up after extraction, and relative high cost of equipment.

3.4. Other Extraction Methods. The combination of gas-like mass transfer and liquid-like solvating abilities of supercritical fluids is exploited in the extraction method known as supercritical fluid extraction (SFE). In this method, a solvent at its supercritical state is used to speed up extraction by an increased matrix-penetrating ability and enhanced mass transfer potential. Although large industrial application of SFE is often hindered by the trade-off between selectivity and recovery efficiency, this method is still found in routine laboratory applications $[79,119]$. Among the numerous factors that affect performance of this approach, temperature and pressure are key considerations in recovery and selectivity calculations. Machmudah et al. [120] have found that recovery of caffeine and the separation factor of CGA from caffeine were positively correlated with increasing height (pressure) of nonpolar recovery section in the separation system using supercritical carbon dioxide $\left(\mathrm{SCCO}_{2}\right)$ in water. They also found that recovery of caffeine in the $\mathrm{SCCO}_{2}$ phase increased with decreased temperature. This could only be true at pressures below the crossover pressure. Above the crossover pressure ( 200 bar), however, an increase in temperature resulted in an increased recovery as observed in the extraction of caffeine from Robusta coffee husks [39].

Solid-phase microextraction (SPME) was introduced in the 1990s in response to the challenges posed by SPE. It basically involves sorption of an analyte to a commercial fiber coated with polymeric substance, followed by a desorption step using a thermal process or suitable solvent. SPME allows for solvent minimization and provides for higher sample enrichment. Different forms of SPME techniques are practiced, but the headspace type (HS-SPME) is very suitable in the analysis of volatile compounds [121, 122]. Affinity of an analyte towards the fiber can be enhanced by carefully selecting the right polymer coating material [123]. LópezDarias et al. [124] found that poly-( $\left.\mathrm{ViHIm}^{+} \mathrm{Cl}^{-}\right)$gave excellent performance for aromatic alcohols while polyacrylamide coating performed better for heterocyclic aromatics. Temperature and extraction time also influence the performance of this method as noticed in a different experiment where poly-dimethyl-siloxane in combination with divinylbenzene (PDMS/DVB) SPME fiber with a $65 \mu \mathrm{m}$ thick film coating was used for the extraction of caffeine and CGA in coffee [125]. Some of the shortcomings of SPME include leaching of coating material, breaking of fiber, and bending of the syringe support.

\section{Methods for Characterization and Quantification of Bioactive Micronutrients of Coffee}

Due to the economic importance of coffee and its constituent bioactive substances, consumer interest and safety should remain paramount. Therefore, there is an increasing demand for proper quality control for certification of contents and reducing counterfeits and substandard products. To achieve these noble goals, sensitive and accurate analytical methods for both qualitative and quantitative determinations and characterization of chemical substances in coffee are required. There are many analytical procedures (Table 1), including chromatographic, photometric, spectral, and electrochemical methods that are geared toward this end [126, 127].

4.1. Separation-Based Methods. To reduce interference and increase sensitivity, an extract is commonly run through a separation system, followed by detection of separated contents using a suitable detector. Among the many analytical techniques that have been applied in the determination of coffee constituents, high performance liquid chromatography (HPLC), gas chromatography (GC), and capillary electrophoresis (CE), in combination with various detectors, such as ultraviolet/visible (UV/Vis) detector, diode array detector (DAD), refractive index (RI) detector, and chemiluminescence detector, are often applied for the determination of nonvolatile, volatile, polar, and nonpolar classes of analytes.

4.1.1. HPLC Methods. This is one of the most powerful tools available for analytical applications in many fields. Because of its versatility, low limits of detection (LOD), and accessibility, its applications can now be found in numerous methods for the analyses of industrial chemicals, agroallied chemicals, and constituents of foods and beverages. It is the single most applied separation-based method of quantification for bioactive constituents in coffee and coffee products. A HPLCbased method for TRG determination and for the quality control of coffee products was explained by Liu et al. [118]. After its separation, TRG was detected at $260 \mathrm{~nm} \lambda$. The total contents of CGA and its isomers in a cup of certified Italian Espresso coffee were between 1522.5 and $2223.4 \mathrm{mgKg}^{-1}$ as determined by HPLC-DAD [110]. Results of HPLC-UV/RI analysis of 17 Brazilian Arabica cultivars have revealed that 
TABLE 1: Analytical methods for characterization and quantification of bioactive micronutrients in coffee.

\begin{tabular}{|c|c|c|c|}
\hline Micronutrient & Method & Figure of merit & Reference \\
\hline CGA & SWV & LOD $\left(0.049 \mu \mathrm{g} \mathrm{mL}^{-1}\right)$ & Yardim, 2012 [141] \\
\hline CGA, caffeine & UV-Vis & $\% \mathrm{R}^{\mathrm{a}}(91-98.43 \%), \mathrm{CV}^{\mathrm{b}}(2.80-5.45 \%)$ & Belay and Gholap, 2009 [105] \\
\hline TRG & HPLC & $\% \mathrm{R}(>90 \%), \% \mathrm{RSD}(<3 \%)$ & Liu et al., 2011 [118] \\
\hline Caffeine & NIR/chemometrics & \%RSD (1.707\%), RMSEP (0.378 mg/g) & Zhang et al., 2013 [152] \\
\hline TRG, caffeine & HPLC & LOD $(0.02 \mathrm{mg} / \mathrm{L}), \mathrm{LOQ}(0.005 \%)$ & Hongcheng et al., 2012 [114] \\
\hline Caffeine & DART-TOFMS & $\% \mathrm{R}(97-107 \%), \% \mathrm{RSD}(<5 \%)$ & Danhelova et al., 2012 [101] \\
\hline TRG, caffeine & ${ }^{1} \mathrm{H}-\mathrm{NMR}$ & $\mathrm{CV}(2.4,4.2 \%), \mathrm{LOD}(0.58,1.32 \mathrm{mg} / \mathrm{g})$ & del Campo et al., 2010 [156] \\
\hline CGA & DPP, SWV & LOD $\left(0.236 \mu \mathrm{molL}^{-1}, 1.34 \mathrm{nmolL}^{-1}\right)$ & Araújo et al., 2009 [144] \\
\hline CGA isomers & 2D-NMR & \%R (75-80\%), R² (0.9960-0.9994) & Wei et al., 2010 [155] \\
\hline Caffeine & CE, HPLC & LOD $(0.87,0.021 \mathrm{mg} / 100 \mathrm{~g}), \% \mathrm{RSD}(<2 \%)$ & Bizzotto et al., 2013 [137] \\
\hline Caffeine & $\mathrm{CV}^{\mathrm{c}}$ & $\operatorname{LOD}\left(0.348 \mu \mathrm{molL}^{-1}\right), \mathrm{R}^{2}(0.999)$ & Mersal, 2012 [142] \\
\hline Caffeine & $\mathrm{CE}$ & $\% \operatorname{RSD}(<2 \%)$ & Li et al., 2009 [139] \\
\hline CGA & DPV & LOD $\left(0.148 \mu \mathrm{molL}^{-1}\right)$ & Santos et al., 2011 [146] \\
\hline CGA isomers & HPLC & $\% \mathrm{R}(67-99 \%), \mathrm{R}^{2}(>0.99)$ & Caprioli et al., 2013 [110] \\
\hline CGA & Biosensor/SWV & LOD $\left(0.915 \mu \mathrm{molL}^{-1}\right), \% \mathrm{R}(93.2-105.7 \%)$ & Fernandes et al., 2009 [147] \\
\hline Cafestol, kahweol & HPLC & $\% \operatorname{RSD}(<5 \%)$ & Sridevi et al., 2011 [71] \\
\hline Caffeine & $\mathrm{CV} / \mathrm{SWV}$ & LOD $\left(0.137 \mu \mathrm{molL}^{-1}\right), \% \mathrm{R}(>90 \%)$ & Amare and Admassie, 2012 [145] \\
\hline
\end{tabular}

${ }^{\mathrm{a}}$ Percent recovery, ${ }^{\mathrm{b}}$ coefficient of variation, ${ }^{\mathrm{c}}$ cyclic voltammetry.

semidry processing method showed lower levels of CGA and TRG than coffee processed by wet method, which goes to confirm the effect of different processing methods on constituents of coffee [128]. In another experiment, HPLC$\mathrm{UV} / \mathrm{Vis}$ analysis revealed that coffee contains $0.06-2.55 \%$ caffeine and this value decreases with roasting intensity [129].

HPLC can be performed in either reverse or normal phase mode. A caffeine assessment tool (CAT) was developed with results obtained from a reverse-phase- (RP-) HPLC-UV analysis of several coffee and coffee-based beverages [130]. Moreira and Scarminio [131] have applied RP-HPLC-DAD for the determination of caffeine at $275 \mathrm{~nm} \lambda$ using a binary ethanol-dichloromethane solution $(1: 1)$ as mobile phase. Mobile phase in gradient flow mode is often employed to resolve complex mixtures. When different coffee extraction methods were tested using a mixture of $0.1 \%$ formic acid in water and $0.1 \%$ formic acid in acetonitrile in this type of flow mode, CGA and caffeine contents of the different extracts were different, confirming that contents may vary according to method of extraction [125].

Two-dimensional HPLC (2D-HPLC) may provide for better resolution than in ordinary practice. The application of this system in combination with chemiluminescence detector allowed for increased sensitivity and better selectivity in the determination of antioxidant constituents of three Espresso coffees ("Ristretto," "Decaffeinato," and "Volluto") [132]. Elsewhere, a C-18 and Bondapak $\mathrm{NH}_{2}$ columns in series were used for the simultaneous determination of TRG, caffeine, and nicotinic acid [114]. This method selected conditions optimal at $120^{\circ} \mathrm{C}$ and $200 \mathrm{psi}$, and good separation was achieved in just $3 \mathrm{~min}$, driven by $0.02 \mathrm{M}$ phosphoric acidmethanol $(70: 30, \mathrm{v} / \mathrm{v})$ mobile phase at $0.8 \mathrm{~mL} / \mathrm{min}$.

Apart from the common detection systems (UV/Vis, $\mathrm{DAD}$, and RI) often employed in liquid chromatographic applications for the characterization of these coffee contents, applications of MS detection are also found in the literature. By a careful selection of parameters, molecular markers for distinguishing between different coffee samples or between constituents can be assigned [133]. In a method of liquid chromatography/multistage spectrometry (LC/ $\left.\mathrm{MS}^{n}\right)(n=2-4)$ described by Jaiswal and Kuhnert [134], hitherto unreported isomers of CGA (triacyl CGAs) were detected in Robusta coffee bean extracts and their structures assigned using LC/MS ${ }^{n}$ fragmentation patterns. In combination with similar fragmentation patterns $\left(\mathrm{LC} / \mathrm{MS}^{n}\right.$, $n=2-3$ ), relative hydrophobicity and fragmentation analogy were also harnessed to distinguish between two isomeric classes of CGA (CGA lactones and cinnamoylshikimate) which are formed from CGA by loss of water at high processing temperatures [135]. Interestingly, a high temperature reverse phase liquid chromatography coupled with isotope ratio mass spectrometry (HT-RPLC/IRMS) was employed to distinguish between natural and synthetic caffeine in coffee drinks, without the painful need for extraction, by using $\delta^{13} \mathrm{C}$ values (between 25 and 32\%ofor natural caffeine, and between 33 and $38 \%$ ofor synthetic caffeine) as distinguishable groups [136]. This method will be a special aid in the fight against counterfeiting and adulteration of coffee products.

4.1.2. CE and Other Methods. CE uses a very small diameter bore capillary to effect separation of charged analytes dissolved in a suitable buffer. The driving force for this separation system is the use of high voltage that influences electrokinetic migration of analytes to either of the positive and negative poles. Hence, a candidate analyte for CE must possess a net negative or positive charge for effective separation. In the last five years, CE has been applied in many fields including the analysis of plant materials [86]. While HPLC did provide 
lower values of LOD for the determination of caffeine in decaffeinated coffee than CE, the latter was 30\% faster, had lower cost of reagents, and generated smaller volumes of residues [137]. In a similar experiment, a fast hydrodynamic injection ( $50 \mathrm{mBar}, 7 \mathrm{~s}$ ) was applied in the analysis of caffeine in commercial decaffeinated coffee using a $48 \mathrm{~cm} \times 50 \mu \mathrm{m}$ fused-silica capillary [138]. Other optimized conditions for this method include a mixture of sodium carbonate (10 $\left.\mathrm{mmolL}^{-1}\right)$ and sodium dodecyl sulfate $\left(50 \mathrm{mmolL}^{-1}\right)$ as buffer, $15 \mathrm{kV}$ voltage, and $206 \mathrm{~nm} \lambda$. Elsewhere, Li et al. [139] have explained a CE method for the determination of caffeine in roasted coffee. This method is characterized by extremely high precision; percent relative standard deviation (\%RSD) was less than $0.8 \%$ for retention time and $1.7 \%$ for peak areas.

GC determination can be extremely important, especially in the analysis of volatile components of coffee [108, 121]. For semivolatile and nonvolatile portions, however, alternative methods will be more desirable and effective. One of such methods is based countercurrent chromatography (CCC), which differs significantly from the preceding types of separation systems by not involving any solid support. Instead, two immiscible solvents are used, one solvent apiece for the stationary and mobile phases. This is exemplified in the method of Machmudah et al. [120] where $\mathrm{SCCO}_{2}$ and water were used, in countercurrent flow mode, to effect the separation of CGA from caffeine. Recently, a method based on the high-speed mode (HSCCC), which could be used for the preparative isolation of milligram amount of CGA from coffee, was explained [140].

4.2. Separation-Less Methods. In many instances, determination of analytes is performed without the need to go through a separation step. Molecular behaviors, such as mass fragmentation patterns, magnetic resonance, electrical properties, and UV/Vis or IR absorbance, are used for their direct characterization and/or quantification. These methods can be defined by extremely low LODs, high throughput, and good selectivity and sensitivity in their applications to the analysis of coffee micronutrients.

4.2.1. Spectroscopic Methods. These methods are based on light-absorbing or light-emitting properties of molecules as they interact with electromagnetic radiation. As a molecule absorbs light energy of defined wavelength, electronic transition characteristic of that molecule is elicited, and this can be used for the characterization and quantification of such molecule. At $324 \mathrm{~nm}$, CGA has a strong $\pi-\pi^{*}$ transition resulting from the delocalized electrons on benzene ring, and this was used for its characterization and quantification in coffee bean extract [105]. Null hypothesis was obeyed between the results obtained by this method and results of HPLC analysis.

Many determinations of antioxidant activities in coffee by different mechanisms are based on UV/Vis absorption spectroscopy [113]. CGA and caffeine are among the main antioxidant micronutrients in coffee. Their antioxidant capacities were measured using $2,2^{\prime}$-azino-bis(3-ethylbenzothiazoline-6-sulphonic acid (ABTS), 2,2-diphenyl-1-picrylhydrazyl
(DPPH), and Folin-Ciocalteau [102]. In a similar investigation, antioxidant capacities of these hydrophilic compounds were also investigated using disodium nitrosodisulfonate (Frémy's salt) and 2,2,6,6-tetramethyl-1-piperidinyloxy (TEMPO), and results for different coffee brewing techniques were obtained as $46.0-102.3 \%$ (Filter), <42\% (Plunger), and 85.6\% (Espresso) [98]. DPPH-radical scavenging activity greater than $75 \%$ was recorded in the extract of green coffee beans containing 22-40\% caffeine and 31-62 CGA [115].

4.2.2. Electrochemical Methods. Oxidation-reduction behaviors of analytes at electrode surfaces may be used for the characterization of such analytes based on their specific relationships with potential and current, or other electrical quantities. Different types of voltammetry and coulometry have been applied in the determination of coffee constituents with high sensitivity, selectivity, and speed. For instance, oxidation of CGA at the surface of boron-doped diamond electrode, using adsorptive transfer stripping voltammetric conditions, was applied for the electrochemical estimation of antioxidant properties of coffee samples with very low LOD $(49 \mathrm{ng} / \mathrm{mL})$ and good linearity within the concentration range of $0.25-4.00 \mu \mathrm{g} / \mathrm{mL}$ [141]. Direct determination of caffeine was achieved by square-wave voltammetry (SWV) using a highly selective pseudo carbon paste electrode versus SCE [142].

Different additives may influence the performance of these methods in several ways. While milk proteins (casein and bovine serum albumin) formed complexes with polyphenolic constituents in coffee thereby significantly reducing their available $\mathrm{OH}$ groups, and thus their antioxidant capacities, as revealed by coulometric titration with hexacyanoferrate (III) ions [143]; addition of cationic surfactant (cetyltrimethylammonium bromide) in the supporting electrolyte $\left(0.04 \mathrm{~mol} \mathrm{~L}^{-1}\right.$ phosphate buffer, $\mathrm{pH}$ 6.0) significantly enhanced the reduction of caffeine at hanging mercury drop electrode, determined by both differential-pulse polarography (DPP) and SWV [144]. When the surface of a glassy carbon electrode was modified by the deposition of thin film of 4-amino-3-hydroxynaphthalene sulfonic acid (AHNSA), highly selective electrocatalyzed oxidation of caffeine was achieved leading to its high recoveries in coffee extracts [145].

Recently, an electrochemical sensor for the selective determination of CGA in coffee samples by differential pulse voltammetry (DPV) was constructed from the deposition of a thin film of molecularly imprinted siloxane (MIS) on gold surface [146]. In a similar application by Fernandes et al. [147], CGA was selectively determined by SWV at $+0.25 \mathrm{~V}$ (versus $\mathrm{Ag} / \mathrm{AgCl}$ ) using a biosensor constructed from 1-nbutyl-3-methylimidazolium hexafluorophosphate containing dispersed iridium nanoparticles (Ir-BMI.PF 6 ) and polyphenol oxidase.

4.2.3. Spectral Methods. Analytical characterization and quantification can also be achieved through stand-alone spectral revelations. MS fragmentation patterns, under different ionization modes, have been employed in chemical analysis, including analysis of components of coffee [148]. 
Direct analysis in real time (DART) coupled to time-offlight mass spectrometry (TOFMS) yielded a high throughput $(<1$ min per run) analysis of caffeine in coffee samples [101]. Without the need for sample preparation or chromatographic separation, the molecular ion $(\mathrm{M}+\mathrm{H})^{+}$resulting from the method of DART-MS was used for the identification of caffeine in commercial instant coffee samples [149]. Caffeine has a mass to charge ratio $(m / z)$ of 194 , and its characterization alongside kahweol $(m / z, 296)$ and cafestol $(m / z, 298)$, two marker compounds for $C$. arabica and C. canephora, was achieved in the method of single photon ionization coupled with TOFMS (SPI-TOFMS) developed by HertzSchünemann et al. [150] for the recognition of roasting gas profiles of coffee.

Characterization of bioactive components of coffee can also be achieved by using their near-IR (NIR) (2500$4000 \mathrm{~cm}^{-1}$ ) absorption spectra. Methods based on this approach are nondestructive and can offer reliable speed of determination. In addition to qualitative analysis, chemometric models can assist in quantitative interpretation of NIR spectral data. In one example, caffeine, TRG, and CGA were determined as components of sensory quality in Arabica roasted coffee samples using ordered prediction selection (OPS) algorithm, partial least squares (PLS), and NIR spectra [151]. Recently, Zhang et al. [152] developed an improved regression model for NIR determination of caffeine. This method is characterized by root mean square error of cross validation (RMSECV) of $0.375 \mathrm{mg} / \mathrm{g}, \% \mathrm{RSD}$ of $1.707 \%$, and correlation coefficient of 0.918 at PLS factor of 7.

For some time now, nuclear magnetic resonance (NMR) spectrometry has been offering good information for the identification and structural elucidation of compounds, and this has now been extended to coffee constituents. Using ${ }^{1} \mathrm{H}$ NMR and partial least squares discriminant analysis (OPLSDA) models, TRG and CGA were found among the main metabolites that can characterize and separate C. arabica samples according to their geographical origin [153]. Recently, structures of CGA lactones, which hitherto were not available in the literature, were established from NMR data [140]. Self-association and complexation of coffee constituents, both in coffee brews and in aqueous media, can pose serious challenge for their analytical resolutions. D'Amelio et al. [154] have investigated structural features of CGAcaffeine complexation using high resolution ${ }^{1} \mathrm{H}-\mathrm{NMR}$. NMR can also offer quantitative information on chemical components in coffee. Without a nuclear Overhauser effect, three isomers of CGA were identified and quantified in green coffee bean extract through integration of 2D NMR carbon signals by use of relaxation reagent and inverse-gated decoupling method [155]. According to del Campo et al. [156], caffeine and TRG, among other constituents of coffee, can be quantitatively analyzed by use of their singlet ${ }^{1} \mathrm{H}-\mathrm{NMR}$ signals within 7.6-9.5 ppm and the use of 3-(trimethylsilyl)2,2,3,3-tetradeuteropropionic acid both as internal standard and as reference for $\delta=0.00 \mathrm{ppm}$.

\section{Conclusions}

Coffee is a popular beverage that is obtained from different varieties of coffee beans. This important drink contains many micronutrients, some of which have proven bioactivities, such as anticancer, antimicrobial, antioxidant, and host of other effects. Four important groups of these biologically important micronutrients, namely, caffeine, CGA, diterpenes, and TRG, have been discussed in this review. Because of their importance in biological systems, recent analytical methods for their characterization and quantitative determination have also been reviewed. It is envisaged that proper applications of these methods will go a long way in aiding quality assurance and safeguarding consumer safety and satisfaction.

\section{Conflict of Interests}

The author declares that there is no conflict of interests regarding the publication of this paper.

\section{References}

[1] T. C. Salinardi, K. H. Rubin, R. M. Black, and M.-P. StOnge, "Coffee mannooligosaccharides, consumed as part of a free-living, weight-maintaining diet, increase the proportional reduction in body volume in overweight men," The Journal of Nutrition, vol. 140, no. 11, pp. 1943-1948, 2010.

[2] A. L. Oliveira, F. A. Cabral, M. N. Eberlin, and H. M. A. B. Cordello, "Sensory evaluation of black instant coffee beverage with some volatile compounds present in aromatic oil from roasted coffee," Ciencia e Tecnologia de Alimentos, vol. 29, no. 1, pp. 7680, 2009.

[3] J. Miran, "Space, mobility, and translocal connections across the Red Sea area since 1500," Northeast African Studies, vol. 12, no. 1, pp. 9-26, 2012.

[4] K. Hundera, R. Aerts, M. de Beenhouwer et al., "Both forest fragmentation and coffee cultivation negatively affect epiphytic orchid diversity in Ethiopian moist evergreen Afromontane forests," Biological Conservation, vol. 159, pp. 285-291, 2013.

[5] F. Serra, C. G. Guillou, F. Reniero et al., "Determination of the geographical origin of green coffee by principal component analysis of carbon, nitrogen and boron stable isotope ratios," Rapid Communications in Mass Spectrometry, vol. 19, no. 15, pp. 2111-2115, 2005.

[6] P. Moguel and V. M. Toledo, "Biodiversity conservation in traditional coffee systems of Mexico," Conservation Biology, vol. 13, no. 1, pp. 11-21, 1999.

[7] F. Anthony, B. Bertrand, O. Quiros et al., "Genetic diversity of wild coffee (Coffea arabica L.) using molecular markers," Euphytica, vol. 118, no. 1, pp. 53-65, 2001.

[8] A.-M. Klein, I. Steffan-Dewenter, and T. Tscharntke, "Bee pollination and fruit set of Coffea arabica and C. canephora (Rubiaceae)," The American Journal of Botany, vol. 90, no. 1, pp. 153-157, 2003.

[9] A. Lécolier, P. Besse, A. Charrier, T.-N. Tchakaloff, and M. Noirot, "Unraveling the origin of Coffea arabica "Bourbon pointu" from la Réunion: a historical and scientific perspective," Euphytica, vol. 168, no. 1, pp. 1-10, 2009.

[10] D. C. Carvalho, M. R. P. L. Brigagão, M. H. S. Santos, F. B. A. de Paula, A. Giusti-Paiva, and L. Azevedo, "Organic and Conventional Coffea arabica L.: a comparative study of the chemical composition and physiological, biochemical and toxicological effects in Wistar rats," Plant Foods for Human Nutrition, vol. 66, no. 2, pp. 114-121, 2011. 
[11] S. Topik, J. M. Talbot, and M. Samper, "Introduction globalization, neoliberalism, and the latin American coffee societies," Latin American Perspectives, vol. 37, no. 2, pp. 5-20, 2010.

[12] C. M. Tucker, H. Eakin, and E. J. Castellanos, "Perceptions of risk and adaptation: coffee producers, market shocks, and extreme weather in Central America and Mexico," Global Environmental Change, vol. 20, no. 1, pp. 23-32, 2010.

[13] E. G. Burbano, M. G. Wright, N. E. Gillette et al., "Efficacy of traps, lures, and repellents for Xylosandrus compactus (Coleoptera: Curculionidae) and other ambrosia beetles on Coffea arabica plantations and Acacia koa nurseries in Hawaii," Environmental Entomology, vol. 41, no. 1, pp. 133-140, 2012.

[14] C. W. Kathurima, B. M. Gichimu, G. M. Kenji, S. M. Muhoho, and R. Boulanger, "Evaluation of beverage quality and green bean physical characteristics of selected Arabica coffee genotypes in Kenya," African Journal of Food Science, vol. 3, no. 11, pp. 365-371, 2009.

[15] W. J. Rogers, S. Michaux, M. Bastin, and P. Bucheli, "Changes to the content of sugars, sugar alcohols, myo-inositol, carboxylic acids and inorganic anions in developing grains from different varieties of Robusta (Coffea canephora) and Arabica (C. arabica) coffees," Plant Science, vol. 149, no. 2, pp. 115-123, 1999.

[16] R. Teuber, "Geographical indications of origin as a tool of product differentiation: the case of coffee," Journal of International Food and Agribusiness Marketing, vol. 22, no. 3-4, pp. 277-298, 2010.

[17] H. C. Liu, C. F. You, C. Y. Chen, Y. C. Liu, and M. T. Chung, "Geographic determination of coffee beans using multi-element analysis and isotope ratios of boron and strontium," Food Chemistry, vol. 142, pp. 439-445, 2013.

[18] T. Niseteo, D. Komes, A. Belščak-Cvitanović, D. Horžić, and M. Bude, "Bioactive composition and antioxidant potential of different commonly consumed coffee brews affected by their preparation technique and milk addition," Food Chemistry, vol. 134, no. 4, pp. 1870-1877, 2012.

[19] M. Oliveira, S. Casal, S. Morais et al., "Intra- and interspecific mineral composition variability of commercial instant coffees and coffee substitutes: contribution to mineral intake," Food Chemistry, vol. 130, no. 3, pp. 702-709, 2012.

[20] J. A. Vignoli, D. G. Bassoli, and M. T. Benassi, "Antioxidant activity, polyphenols, caffeine and melanoidins in soluble coffee: the influence of processing conditions and raw material," Food Chemistry, vol. 124, no. 3, pp. 863-868, 2011.

[21] S. I. Mussatto, L. M. Carneiro, J. P. A. Silva, I. C. Roberto, and J. A. Teixeira, "A study on chemical constituents and sugars extraction from spent coffee grounds," Carbohydrate Polymers, vol. 83, no. 2, pp. 368-374, 2011.

[22] Y. F. Chu, P. H. Brown, B. J. Lyle et al., "Roasted coffees high in lipophilic antioxidants and chlorogenic acid lactones are more neuroprotective than green coffees," Journal of Agricultural and Food Chemistry, vol. 57, no. 20, pp. 9801-9808, 2009.

[23] S. Johnson, W. P. Koh, R. Wang, S. Govindarajan, M. C. Yu, and J. M. Yuan, "Coffee consumption and reduced risk of hepatocellular carcinoma: findings from the Singapore Chinese Health Study," Cancer Causes and Control, vol. 22, no. 3, pp. 503-510, 2011.

[24] J. Tai, S. Cheung, E. Chan, and D. Hasman, "Antiproliferation effect of commercially brewed coffees on human ovarian cancer cells in vitro," Nutrition and Cancer, vol. 62, no. 8, pp. 1044-1057, 2010.
[25] G. W. Arendash and C. Cao, "Caffeine and coffee as therapeutics against Alzheimer's disease," Journal of Alzheimer's Disease, vol. 20, no. 1, pp. 117-126, 2010.

[26] U. Boettler, K. Sommerfeld, N. Volz et al., "Coffee constituents as modulators of Nrf2 nuclear translocation and ARE (EpRE)dependent gene expression," Journal of Nutritional Biochemistry, vol. 22, no. 5, pp. 426-440, 2011.

[27] A. S. Doré, N. Robertson, J. C. Errey et al., "Structure of the adenosine $\mathrm{A}_{2 \mathrm{~A}}$ receptor in complex with ZM241385 and the xanthines XAC and caffeine," Structure, vol. 19, no. 9, pp. 12831293, 2011.

[28] M. A. Heckman, J. Weil, and E. G. de Mejia, "Caffeine (1, 3, 7trimethylxanthine) in foods: a comprehensive review on consumption, functionality, safety, and regulatory matters," Journal of Food Science, vol. 75, no. 3, pp. R77-R87, 2010.

[29] N. Amaresh, A. R. Mullaicharam, and M. A. El-Khider, "Chemistry and pharmacology of caffeine in different types of tea leaves," International Journal of Nutrition, Pharmacology, Neurological Diseases, vol. 1, no. 2, pp. 110-115, 2011.

[30] L. Wang, L.-H. Gong, C.-J. Chen, H.-B. Han, and H.-H. Li, "Column-chromatographic extraction and separation of polyphenols, caffeine and theanine from green tea," Food Chemistry, vol. 131, no. 4, pp. 1539-1545, 2012.

[31] Q. V. Vuong and P. D. Roach, "Caffeine in green tea: its removal and isolation," Separation and Purification Reviews, vol. 43, no. 2, pp. 155-174, 2014.

[32] M. C. Borges, M. A. R. Vinolo, K. Nakajima et al., "The effect of mate tea (Ilex paraguariensis) on metabolic and inflammatory parameters in high-fat diet-fed Wistar rats," International Journal of Food Sciences and Nutrition, vol. 64, no. 5, pp. 561-569, 2013.

[33] V. Olmos, N. Bardoni, A. S. Ridolfi, and E. C. Villaamil Lepori, "Caffeine levels in beverages from Argentina's market: application to caffeine dietary intake assessment," Food Additives and Contaminants A, vol. 26, no. 3, pp. 275-281, 2009.

[34] S. Oba, C. Nagata, K. Nakamura et al., "Consumption of coffee, green tea, oolong tea, black tea, chocolate snacks and the caffeine content in relation to risk of diabetes in Japanese men and women," British Journal of Nutrition, vol. 103, no. 3, pp. 453459, 2010.

[35] S. N. Bhupathiraju, A. Pan, V. S. Malik et al., "Caffeinated and caffeine-free beverages and risk of type 2 diabetes," The American Journal of Clinical Nutrition, vol. 97, pp. 155-166, 2013.

[36] C. J. Reissig, E. C. Strain, and R. R. Griffiths, "Caffeinated energy drinks-a growing problem," Drug and Alcohol Dependence, vol. 99, no. 1-3, pp. 1-10, 2009.

[37] R. S. J. Keast, D. Sayompark, G. Sacks, B. A. Swinburn, and L. J. Riddell, "The influence of caffeine on energy content of sugarsweetened beverages: 'the caffeine-calorie effect,' European Journal of Clinical Nutrition, vol. 65, no. 12, pp. 1338-1344, 2011.

[38] P. Mazzafera and M. B. Silvarolla, "Caffeine content variation in single green Arabica coffee seeds," Seed Science Research, vol. 20, no. 3, pp. 163-167, 2010.

[39] J. Tello, M. Viguera, and L. Calvo, "Extraction of caffeine from Robusta coffee (Coffea canephora var. Robusta) husks using supercritical carbon dioxide," Journal of Supercritical Fluids, vol. 59, pp. 53-60, 2011.

[40] G. Laurence, K. Wallman, and K. Guelfi, "Effects of caffeine on time trial performance in sedentary men," Journal of Sports Sciences, vol. 30, no. 12, pp. 1235-1240, 2012. 
[41] R. D. S. Prediger, "Effects of caffeine in Parkinson's disease: from neuroprotection to the management of motor and non-motor symptoms," Journal of Alzheimer's Disease, vol. 20, no. 1, pp. 205-220, 2010.

[42] Y. F. Chu, W. H. Chang, R. M. Black et al., "Crude caffeine reduces memory impairment and amyloid $\beta 1-42$ levels in an Alzheimer's mouse model," Food Chemistry, vol. 135, no. 3, pp. 2095-2102, 2012.

[43] Y. F. Chu, Y. Chen, P. H. Brown et al., "Bioactivities of crude caffeine: antioxidant activity, cyclooxygenase-2 inhibition, and enhanced glucose uptake," Food Chemistry, vol. 131, no. 2, pp. 564-568, 2012.

[44] W. Dworzański, G. Opielak, and F. Burdan, "Side effects of caffeine," Polski Merkuriusz Lekarski, vol. 7, no. 161, pp. 357-361, 2009.

[45] P. J. Rogers, S. V. Heatherley, E. L. Mullings, and J. E. Smith, "Faster but not smarter: effects of caffeine and caffeine withdrawal on alertness and performance," Psychopharmacology, vol. 226, no. 2, pp. 229-240, 2013.

[46] Y. Narita and K. Inouye, "Degradation kinetics of chlorogenic acid at various $\mathrm{pH}$ values and effects of ascorbic acid and epigallocatechin gallate on its stability under alkaline conditions," Journal of Agricultural and Food Chemistry, vol. 61, no. 4, pp. 966-972, 2013.

[47] P. Górnas, G. Neunert, K. Baczyński, and K. Polewski, "Betacyclodextrin complexes with chlorogenic and caffeic acids from coffee brew: spectroscopic, thermodynamic and molecular modelling study," Food Chemistry, vol. 114, no. 1, pp. 190-196, 2009.

[48] R. Upadhyay and L. J. M. Rao, "An outlook on chlorogenic acids-occurrence, chemistry, technology, and biological activities," Critical Reviews in Food Science and Nutrition, vol. 53, no. 9, pp. 968-984, 2013.

[49] M. Zhao, H. Wang, B. Yang, and H. Tao, "Identification of cyclodextrin inclusion complex of chlorogenic acid and its antimicrobial activity," Food Chemistry, vol. 120, no. 4, pp. 1138-1142, 2010.

[50] A. A. Memon, N. Memon, D. L. Luthria, M. I. Bhanger, and A. A. Pitafi, "Phenolic acids profiling and antioxidant potential of mulberry (Morus laevigata W., Morus nigra L., Morus alba L.) leaves and fruits grown in Pakistan," Polish Journal of Food and Nutrition Sciences, vol. 60, no. 1, pp. 25-32, 2010.

[51] T. Joët, J. Salmona, A. Laffargue, F. Descroix, and S. Dussert, "Use of the growing environment as a source of variation to identify the quantitative trait transcripts and modules of coexpressed genes that determine chlorogenic acid accumulation," Plant, Cell and Environment, vol. 33, no. 7, pp. 1220-1233, 2010.

[52] J.-K. Moon, H. S. Yoo, and T. Shibamoto, "Role of roasting conditions in the level of chlorogenic acid content in coffee beans: correlation with coffee acidity," Journal of Agricultural and Food Chemistry, vol. 57, no. 12, pp. 5365-5369, 2009.

[53] M. T. L. Kreuml, D. Majchrzak, B. Ploederl, and J. Koenig, "Changes in sensory quality characteristics of coffee during storage," Food Science and Nutrition, vol. 1, no. 4, pp. 267-272, 2013.

[54] K. W. Ong, A. Hsu, and B. K. H. Tan, "Anti-diabetic and antilipidemic effects of chlorogenic acid are mediated by ampk activation," Biochemical Pharmacology, vol. 85, no. 9, pp. 1341-1351, 2013.

[55] A.-S. Cho, S.-M. Jeon, M.-J. Kim et al., "Chlorogenic acid exhibits anti-obesity property and improves lipid metabolism in high-fat diet-induced-obese mice," Food and Chemical Toxicology, vol. 48, no. 3, pp. 937-943, 2010.

[56] Y. Sato, S. Itagaki, T. Kurokawa et al., "In vitro and in vivo antioxidant properties of chlorogenic acid and caffeic acid," International Journal of Pharmaceutics, vol. 403, no. 1-2, pp. 136138, 2011.

[57] C. Hoelzl, S. Knasmüller, K.-H. Wagner et al., "Instant coffee with high chlorogenic acid levels protects humans against oxidative damage of macromolecules," Molecular Nutrition and Food Research, vol. 54, no. 12, pp. 1722-1733, 2010.

[58] S.-H. Kwon, H.-K. Lee, J.-A. Kim et al., "Neuroprotective effects of chlorogenic acid on scopolamine-induced amnesia via anti-acetylcholinesterase and anti-oxidative activities in mice," European Journal of Pharmacology, vol. 649, no. 1-3, pp. 210-217, 2010.

[59] G.-F. Wang, L.-P. Shi, Y.-D. Ren et al., "Anti-hepatitis B virus activity of chlorogenic acid, quinic acid and caffeic acid in vivo and in vitro," Antiviral Research, vol. 83, no. 2, pp. 186-190, 2009.

[60] T. Urushisaki, T. Takemura, S. Tazawa et al., "Caffeoylquinic acids are major constituents with potent anti-influenza effects in brazilian green propolis water extract," Evidence-based Complementary and Alternative Medicine, vol. 2011, Article ID 254914, 7 pages, 2011.

[61] C.-M. Ma, T. Kawahata, M. Hattori, T. Otake, L. Wang, and M. Daneshtalab, "Synthesis, anti-HIV and anti-oxidant activities of caffeoyl 5,6-anhydroquinic acid derivatives," Bioorganic and Medicinal Chemistry, vol. 18, no. 2, pp. 863-869, 2010.

[62] Z. Lou, H. Wang, S. Zhu, C. Ma, and Z. Wang, "Antibacterial activity and mechanism of action of chlorogenic acid," Journal of Food Science, vol. 76, no. 6, pp. M398-M403, 2011.

[63] M. Villarino, P. Sandín-España, P. Melgarejo, and A. de Cal, "High chlorogenic and neochlorogenic acid levels in immature peaches reduce Monilinia laxa infection by interfering with fungal melanin biosynthesis," Journal of Agricultural and Food Chemistry, vol. 59, no. 7, pp. 3205-3213, 2011.

[64] M. Ashour, M. Wink, and J. Gershenzon, "Biochemistry of terpenoids: monoterpenes, sesquiterpenes and diterpenes," in Annual Plant Review, M. Wink, Ed., vol. 40 of Biochemistry of Plant Secondary Metabolism, pp. 258-303, Wiley-Blackwell, Oxford, UK, 2nd edition, 2010.

[65] I. Córdova-Guerrero, L. S. Andrés, A. E. Leal-Orozco, J. M. Padrón, J. M. Cornejo-Bravo, and F. León, "New strategy toward the diverted synthesis of oxidized abietane diterpenes via oxidation of 6, 7-dehydroferruginol methyl ether with dimethyldioxirane," Tetrahedron Letters, vol. 54, no. 33, pp. 44794482, 2013.

[66] B. Yang, X.-F. Zhou, X.-P. Lin et al., "Cembrane diterpenes chemistry and biological properties," Current Organic Chemistry, vol. 16, no. 12, pp. 1512-1539, 2012.

[67] C. M. Gampe and E. M. Carreira, "Cyclohexyne cycloinsertion in the divergent synthesis of guanacastepenes," Chemistry, vol. 18, no. 49, pp. 15761-15771, 2012.

[68] P. de Araújo Rodrigues, S. M. de Morais, C. M. de Souza et al., "Gastroprotective effect of barbatusin and 3-beta-hydroxy3-deoxibarbatusin, quinonoid diterpenes isolated from Plectranthus grandis, in ethanol-induced gastric lesions in mice," Journal of Ethnopharmacology, vol. 127, no. 3, pp. 725-730, 2010.

[69] R. K. Devappa, H. P. S. Makkar, and K. Becker, "Jatropha diterpenes: a review," Journal of the American Oil Chemists' Society, vol. 88, no. 3, pp. 301-322, 2011. 
[70] K. A. Lee, J. I. Chae, and J. H. Shim, "Natural diterpenes from coffee, cafestol and kahweol induce apoptosis through regulation of specificity protein 1 expression in human malignant pleural mesothelioma," Journal of Biomedical Science, vol. 19, no. 60, pp. 1-10, 2012.

[71] V. Sridevi, P. Giridhar, and G. A. Ravishankar, "Evaluation of roasting and brewing effect on antinutritional diterpenes-cafestol and kahweol in coffee," Global Journal of Medical Research, vol. 11, no. 5, pp. 1-7, 2011.

[72] F. He and W. Harding, "New labdane diterpenes from Leonotis leonurus and their biological activities," Planta Medica, vol. 78, no. 11, 2012.

[73] L. Faiella, F. D. Piaz, A. Bisio, A. Tosco, and N. de Tommasi, "A chemical proteomics approach reveals Hsp27 as a target for proapoptotic clerodane diterpenes," Molecular BioSystems, vol. 8, pp. 2637-2644, 2012.

[74] F. P. Miao, X. R. Liang, X. L. Yin, G. Wang, and N. Y. Ji, “Absolute configurations of unique harziane diterpenes from Trichoderma species," Organic Letters, vol. 14, no. 15, pp. 3815-3817, 2012.

[75] M. J. Schnermann, C. M. Beaudry, N. E. Genung et al., "Divergent synthesis and chemical reactivity of bicyclic lactone fragments of complex rearranged spongian diterpenes," Journal of the American Chemical Society, vol. 133, no. 43, pp. 17494-17503, 2011.

[76] E. P. Stout, L. C. Yu, and T. E. Molinski, "Antifungal diterpene alkaloids from the Caribbean sponge Agelas citrina: unified configurational assignments of agelasidines and agelasines," European Journal of Organic Chemistry, no. 27, pp. 5131-5135, 2012.

[77] F. D. Piaz, R. Cotugno, L. Lepore et al., "Chemical proteomics reveals HSP70 1A as a target for the anticancer diterpene oridonin in Jurkat cells," Journal of Proteomics, vol. 82, no. 26, pp. 14-26, 2013.

[78] M. Fronza, E. Lamy, S. Günther, B. Heinzmann, S. Laufer, and I. Merfort, "Abietane diterpenes induce cytotoxic effects in human pancreatic cancer cell line MIA PaCa-2 through different modes of action," Phytochemistry, vol. 78, pp. 107-119, 2012.

[79] S. Glisic, J. Ivanovic, M. Ristic, and D. Skala, "Extraction of sage (Salvia officinalis L.) by supercritical $\mathrm{CO}_{2}$ : kinetic data, chemical composition and selectivity of diterpenes," Journal of Supercritical Fluids, vol. 52, no. 1, pp. 62-70, 2010.

[80] D. N. Cavalcanti, M.-A. R. de Oliveira, J. C. de-Paula et al., "Variability of a diterpene with potential anti-HIV activity isolated from the Brazilian brown alga Dictyota menstrualis," Journal of Applied Phycology, vol. 23, no. 5, pp. 873-876, 2011.

[81] S. J. Greay and K. A. Hammer, "Recent developments in the bioactivity of mono- and diterpenes: anticancer and antimicrobial activity," Phytochemistry Reviews, pp. 1-6, 2011.

[82] C. L. Céspedes, J. R. Salazar, and J. Alarcon, "Chemistry and biological activities of Calceolaria spp. (Calceolariaceae: scrophulariaceae)," Phytochemistry Reviews, vol. 12, no. 4, pp. 733749, 2013.

[83] L. Rakotobe, K. Mezhoud, M. Berkal et al., "Acute toxic effects of 8-epidiosbulbin E, a 19-norclerodane diterpene from yam Dioscorea antaly, on medaka Oryzias latipes embryos," Journal of Fish Biology, vol. 77, no. 4, pp. 870-878, 2010.

[84] J. Zhou, L. Chan, and S. Zhou, “Trigonelline: a plant alkaloid with therapeutic potential for diabetes and central nervous system disease," Current Medicinal Chemistry, vol. 19, no. 21, pp. 3523-3531, 2012.
[85] K. F. Allred, K. M. Yackley, J. Vanamala, and C. D. Allred, "Trigonelline is a novel phytoestrogen in coffee beans," Journal of Nutrition, vol. 139, no. 10, pp. 1833-1838, 2009.

[86] L. Sánchez-Hernández, P. Puchalska, C. García-Ruiz, A. L. Crego, and M. L. Marina, "Determination of trigonelline in seeds and vegetable oils by capillary electrophoresis as a novel marker for the detection of adulterations in olive oils," Journal of Agricultural and Food Chemistry, vol. 58, no. 13, pp. 7489-7496, 2010.

[87] G. G. Adams, S. Imran, S. Wang et al., “The hypoglycemic effect of pumpkin seeds, trigonelline (TRG), nicotinic acid (NA) and D-chiro-inositol (DCI) in controlling glycaemic levels in diabetes mellitus," Critical Reviews in Food Science and Nutrition, 2013.

[88] Y. Yin, H. Sasamoto, and H. Ashihara, "Pyridine metabolism and trigonelline synthesis in leaves of the mangrove legume trees Derris indica (Millettia pinnata) and Caesalpinia crista," Natural Product Communications, vol. 6, no. 12, pp. 1835-1838, 2011.

[89] M. Mathur and R. Kamal, "Studies on trigonelline from Moringa oleifera and its in vitro regulation by feeding precursor in cell cultures," Revista Brasileira de Farmacognosia, vol. 22, no. 5, pp. 994-1001, 2012.

[90] A. E. van Dijk, M. R. Olthof, J. C. Meeuse, E. Seebus, R. J. Heine, and R. M. van Dam, "Acute effects of decaffeinated coffee and the major coffee components chlorogenic acid and trigonelline on glucose tolerance," Diabetes Care, vol. 32, no. 6, pp. 1023$1025,2009$.

[91] H. Ashihara, W.-W. Deng, and C. Nagai, “Trigonelline biosynthesis and the pyridine nucleotide cycle in Coffea arabica fruits: metabolic fate of [carboxyl- ${ }^{14} \mathrm{C}$ ]nicotinic acid riboside," Phytochemistry Letters, vol. 4, no. 3, pp. 235-239, 2011.

[92] N. C. Bicho, A. E. Leitão, J. C. Ramalho, and F. C. Lidon, "Identification of chemical clusters discriminators of the roast degree in Arabica and Robusta coffee beans," European Food Research and Technology, vol. 233, no. 2, pp. 303-311, 2011.

[93] O. Yoshinari and K. Igarashi, "Anti-diabetic effect of trigonelline and nicotinic acid, on KK-Ay mice," Current Medicinal Chemistry, vol. 17, no. 20, pp. 2196-2202, 2010.

[94] J. Y. Zhou and S. W. Zhou, "Protection of trigonelline on experimental diabetic peripheral neuropathy," Evidence-Based Complementary and Alternative Medicine, vol. 2012, Article ID 164219, 8 pages, 2012.

[95] A. Arlt, S. Sebens, S. Krebs et al., "Inhibition of the Nrf2 transcription factor by the alkaloid trigonelline renders pancreatic cancer cells more susceptible to apoptosis through decreased proteasomal gene expression and proteasome activity," Oncogene, vol. 32, pp. 4825-4835, 2013.

[96] A. G. Antonio, R. S. Moraes, D. Perrone et al., "Species, roasting degree and decaffeination influence the antibacterial activity of coffee against Streptococcus mutans," Food Chemistry, vol. 118, no. 3, pp. 782-788, 2010.

[97] C. Zhang, R. Linforth, and I. D. Fisk, "Cafestol extraction yield from different coffee brew mechanisms," Food Research International, vol. 49, no. 1, pp. 27-31, 2012.

[98] J. Bravo, I. Juaniz, C. Monente et al., "Evaluation of spent coffee obtained from the most common coffeemakers as a source of hydrophilic bioactive compounds," Journal of Agricultural and Food Chemistry, vol. 60, no. 51, pp. 12565-12573, 2012. 
[99] W. Bi, J. Zhou, and K. H. Row, "Decaffeination of coffee bean waste by solid-liquid extraction," Korean Journal of Chemical Engineering, vol. 28, no. 1, pp. 221-224, 2011.

[100] S. I. Mussatto, L. F. Ballesteros, S. Martins, and J. A. Teixeira, "Extraction of antioxidant phenolic compounds from spent coffee grounds," Separation and Purification Technology, vol. 83, no. 1, pp. 173-179, 2011.

[101] H. Danhelova, J. Hradecky, S. Prinosilova et al., "Rapid analysis of caffeine in various coffee samples employing direct analysis in real-time ionization-high-resolution mass spectrometry," Analytical and Bioanalytical Chemistry, vol. 403, no. 10, pp. 28832889, 2012.

[102] I. A. Ludwig, L. Sanchez, B. Caemmerer, L. W. Kroh, M. P. de Peña, and C. Cid, "Extraction of coffee antioxidants: impact of brewing time and method," Food Research International, vol. 48, no. 1, pp. 57-64, 2012.

[103] W. Mullen, B. Nemzer, B. Ou et al., "The antioxidant and chlorogenic acid profiles of whole coffee fruits are influenced by the extraction procedures," Journal of Agricultural and Food Chemistry, vol. 59, no. 8, pp. 3754-3762, 2011.

[104] F. Pena-Pereira, I. Lavilla, and C. Bendicho, "Miniaturized preconcentration methods based on liquid-liquid extraction and their application in inorganic ultratrace analysis and speciation: a review," Spectrochimica Acta B, vol. 64, no. 1, pp. 1-15, 2009.

[105] A. Belay and A. V. Gholap, "Characterization and determination of chlorogenic acids (CGA) in coffee beans by UV-Vis spectroscopy," African Journal of Pure and Applied Chemistry, vol. 3, no. 11, pp. 234-240, 2009.

[106] S. Shipovskov, K. M. Kragh, B. S. Laursen, C. H. Poulsen, F. Besenbacher, and D. S. Sutherland, "Mannanase transfer into hexane and xylene by liquid-liquid extraction," Applied Biochemistry and Biotechnology, vol. 160, no. 4, pp. 1124-1129, 2010.

[107] A. A. Nuhu, C. Basheer, K. Alhooshani, and A. R. Al-Arfaj, "Determination of phenoxy herbicides in water samples using phase transfer microextraction with simultaneous derivatization followed by GC-MS analysis," Journal of Separation Science, vol. 35, pp. 3381-3388, 2012.

[108] K. Cecilia, K. Glaston, M. Simon, B. Renaud, and N. Fredrick, "Volatile organic compounds in brewed Kenyan Arabica coffee genotypes by solid phase extraction gas chromatography mass spectrometry," Food Science and Quality Management, vol. 8, pp. 18-26, 2012.

[109] H. Fan, Z. Deng, H. Zhong, and Q. Yao, "Development of new solid phase extraction techniques in the last ten years," Journal of Chinese Pharmaceutical Sciences, vol. 22, no. 4, pp. 293-302, 2013.

[110] G. Caprioli, M. Cortese, L. Odello et al., "Importance of espresso coffee machine parameters on the extraction of chlorogenic acids in a certified Italian Espresso by using SPE-HPLC-DAD," Journal of Food Research, vol. 2, no. 3, pp. 55-64, 2013.

[111] G. Spigno and D. M. de Faveri, "Microwave-assisted extraction of tea phenols: a phenomenological study," Journal of Food Engineering, vol. 93, no. 2, pp. 210-217, 2009.

[112] R. C. E. Dias, A. F. Faria, A. Mercadante, N. Bragagnolo, and M. T. Benassi, "Comparison of extraction methods for kahweol and cafestol analysis in roasted coffee," Journal of the Brazilian Chemical Society, vol. 24, no. 3, pp. 492-499, 2013.

[113] M. D. Pavlovic, A. V. Buntic, S. Siler-Marinkovic, and S. I. Dimitrijević-Branković, "Ethanol influenced fast microwaveassisted extraction for natural antioxidants obtaining from spent filter coffee," Separation and Purification Technology, vol. 118, pp. 503-510, 2013.

[114] L. Hongcheng, S. Jinliang, L. Qiwan, L. Yangang, Y. H. Mei, and H. Lizhong, "Determination of trigonelline, nicotinic acid, and caffeine in Yunnan Arabica coffee by microwave-assisted extraction and HPLC with two columns in series," Journal of AOAC International, vol. 95, no. 4, pp. 1138-1141, 2012.

[115] R. Upadhyay, K. Ramalakshmi, and L. J. M. Rao, "Microwaveassisted extraction of chlorogenic acids from green coffee beans," Food Chemistry, vol. 130, no. 1, pp. 184-188, 2012.

[116] J. Xi, D. Shen, S. Zhao, B. Lu, Y. Li, and R. Zhang, "Characterization of polyphenols from green tea leaves using a high hydrostatic pressure extraction," International Journal of Pharmaceutics, vol. 382, no. 1-2, pp. 139-143, 2009.

[117] C.-C. Wang, Y.-Y. Chou, S.-R. Sheu, M.-J. Jang, and T.-H. Chen, "Application of ultrasound thermal process on extracting flavor and caffeine of coffee," Thermal Science, vol. 15, supplement 1, pp. S69-S74, 2011.

[118] H. Liu, Q. Li, J. Shao, H. Yan, and S. Lan, "Determination of trigonelline in coffee powder and instant coffee by ultrasonic extraction and high performance liquid chromatography," Se $P u$, vol. 29, no. 11, pp. 1103-1106, 2011.

[119] L.-H. Wang, Y.-H. Mei, F. Wang, X.-S. Liu, and Y. Chen, "A novel and efficient method combining SFE and liquid-liquid extraction for separation of coumarins from Angelica dahurica," Separation and Purification Technology, vol. 77, no. 3, pp. 397401, 2011.

[120] S. Machmudah, K. Kitada, M. Sasaki, M. Goto, J. Munemasa, and M. Yamagata, "Simultaneous extraction and separation process for coffee beans with supercritical $\mathrm{CO}_{2}$ and water," Industrial and Engineering Chemistry Research, vol. 50, no. 4, pp. 2227-2235, 2011.

[121] C. Petisca, T. Pérez-Palacios, A. Farah, O. Pinho, and I. M. P. V. O. Ferreira, "Furans and other volatile compounds in ground roasted and espresso coffee using headspace solid-phase microextraction: effect of roasting speed," Food and Bioproducts Processing, vol. 91, no. 3, pp. 233-241, 2013.

[122] E. Liberto, M. R. Ruosi, C. Cordero, P. Rubiolo, C. Bicchi, and B. Sgorbini, "Non-separative headspace solid phase microextraction-mass spectrometry profile as a marker to monitor coffee roasting degree," Journal of Agricultural and Food Chemistry, vol. 61, no. 8, pp. 1652-1660, 2013.

[123] J. S. Ribeiro, R. F. Teófilo, F. Augusto, and M. M. C. Ferreira, "Simultaneous optimization of the microextraction of coffee volatiles using response surface methodology and principal component analysis," Chemometrics and Intelligent Laboratory Systems, vol. 102, no. 1, pp. 45-52, 2010.

[124] J. López-Darias, J. L. Anderson, V. Pino, and A. M. Afonso, "Developing qualitative extraction profiles of coffee aromas utilizing polymeric ionic liquid sorbent coatings in headspace solid-phase microextraction gas chromatography-mass spectrometry," Analytical and Bioanalytical Chemistry, vol. 401, no. 9, pp. 2965-2976, 2011.

[125] A. N. Gloess, B. Schönbächler, B. Klopprogge et al., "Comparison of nine common coffee extraction methods: instrumental and sensory analysis," European Food Research and Technology, vol. 236, no. 4, pp. 607-627, 2013.

[126] I. Ignat, I. Volf, and V. I. Popa, "A critical review of methods for characterisation of polyphenolic compounds in fruits and vegetables," Food Chemistry, vol. 126, no. 4, pp. 1821-1835, 2011. 
[127] A. Belay, "Some biochemical compounds in coffee beans and methods developed for their analysis," International Journal of the Physical Sciences, vol. 6, no. 28, pp. 6373-6378, 2011.

[128] G. S. Duarte, A. A. Pereira, and A. Farah, "Chlorogenic acids and other relevant compounds in Brazilian coffees processed by semi-dry and wet post-harvesting methods," Food Chemistry, vol. 118, no. 3, pp. 851-855, 2010.

[129] I. Hečimović, A. Belščak-Cvitanović, D. Horžić, and D. Komes, "Comparative study of polyphenols and caffeine in different coffee varieties affected by the degree of roasting," Food Chemistry, vol. 129, no. 3, pp. 991-1000, 2011.

[130] E. Rudolph, A. Färbinger, and J. König, "Determination of the caffeine contents of various food items within the Austrian market and validation of a caffeine assessment tool (CAT)," Food Additives and Contaminants A, vol. 29, no. 12, pp. 1849-1860, 2012.

[131] I. Moreira and I. S. Scarminio, "Chemometric discrimination of genetically modified Coffea arabica cultivars using spectroscopic and chromatographic fingerprints," Talanta, vol. 107, pp. 416-422, 2013.

[132] M. Mnatsakanyan, P. G. Stevenson, X. A. Conlan et al., "The analysis of café espresso using two-dimensional reversed phasereversed phase high performance liquid chromatography with UV-absorbance and chemiluminescence detection," Talanta, vol. 82, no. 4, pp. 1358-1363, 2010.

[133] N. Kuhnert, R. Jaiswal, P. Eravuchira, R. M. El-Abassy, B. Kammer, and A. Materny, "Scope and limitations of principal component analysis of high resolution LC-TOF-MS data: the analysis of the chlorogenic acid fraction in green coffee beans as a case study," Analytical Methods, vol. 3, no. 1, pp. 144-155, 2011.

[134] R. Jaiswal and N. Kuhnert, "Hierarchical scheme for liquid chromatography/ multi-stage spectrometric identification of 3,4,5-triacyl chlorogenic acids in green Robusta coffee beans," Rapid Communications in Mass Spectrometry, vol. 24, no. 15, pp. 2283-2294, 2010.

[135] R. Jaiswal, M. F. Matei, F. Ullrich, and N. Kuhnert, "How to distinguish between cinnamoylshikimate esters and chlorogenic acid lactones by liquid chromatography-tandem mass spectrometry," Journal of Mass Spectrometry, vol. 46, no. 9, pp. 933942, 2011.

[136] L. Zhang, D. M. Kujawinski, E. Federherr, T. C. Schmidt, and M. A. Jochmann, "Caffeine in your drink: natural or synthetic?" Analytical Chemistry, vol. 84, no. 6, pp. 2805-2810, 2012.

[137] C. S. Bizzotto, A. D. Meinhart, C. A. Ballus, G. Ghiselli, and H. T. Godoy, "Comparison of capillary electrophoresis and high performance liquid chromatography methods for caffeine determination in decaffeinated coffee," Food Science and Technology, vol. 33, no. 1, pp. 186-191, 2013.

[138] A. D. Meinhart, C. S. Bizzotto, C. A. Ballus et al., "Optimisation of a CE method for caffeine analysis in decaffeinated coffee," Food Chemistry, vol. 120, no. 4, pp. 1155-1161, 2010.

[139] M. Li, J. Zhou, X. Gu, Y. Wang, X. J. Huang, and C. Yan, "Quantitative capillary electrophoresis and its application in analysis of alkaloids in tea, coffee, coca cola, and theophylline tablets," Journal of Separation Science, vol. 32, no. 2, pp. 267-274, 2009.

[140] N. Kaiser, D. Birkholz, S. Colomban, L. Navarini, and U. H. Engelhardt, "A new method for the preparative isolation of chlorogenic acid lactones from coffee and model roasts of 5caffeoylquinic acid," Journal of Agricultural and Food Chemistry, vol. 61, no. 28, pp. 6937-6941, 2013.
[141] Y. Yardim, "Electrochemical behavior of chlorogenic acid at a boron-doped diamond electrode and estimation of the antioxidant capacity in the coffee samples based on its oxidation peak," Journal of Food Science, vol. 77, no. 4, pp. C408-C413, 2012.

[142] G. A. M. Mersal, "Experimental and computational studies on the electrochemical oxidation of caffeine at pseudo carbon paste electrode and its voltammetric determination in different real samples," Food Analytical Methods, vol. 5, no. 3, pp. 520-529, 2012.

[143] G. Ziyatdinova, A. Nizamova, and H. Budnikov, "Novel coulometric approach to evaluation of total free polyphenols in tea and coffee beverages in presence of milk proteins," Food Analytical Methods, vol. 4, no. 3, pp. 334-340, 2011.

[144] T. A. Araújo, J. C. Cardoso, A. M. Barbosa, and V. S. Ferreira, "Influence of the surfactant bromide of cetyltrimetyl ammonium in the determination of chlorogenic acid in instant coffee and mate tea samples," Colloids and Surfaces B, vol. 73, no. 2, pp. 408-414, 2009.

[145] M. Amare and S. Admassie, "Polymer modified glassy carbon electrode for the electrochemical determination of caffeine in coffee," Talanta, vol. 93, pp. 122-128, 2012.

[146] W. J. R. Santos, M. Santhiago, I. V. P. Yoshida, and L. T. Kubota, "Novel electrochemical sensor for the selective recognition of chlorogenic acid," Analytica Chimica Acta, vol. 695, no. 1-2, pp. 44-50, 2011.

[147] S. C. Fernandes, S. K. Moccelini, C. W. Scheeren et al., "Biosensor for chlorogenic acid based on an ionic liquid containing iridium nanoparticles and polyphenol oxidase," Talanta, vol. 79, no. 2, pp. 222-228, 2009.

[148] R. Jaiswal, M. F. Matei, A. Golon, M. Witt, and N. Kuhnert, "Understanding the fate of chlorogenic acids in coffee roasting using mass spectrometry based targeted and non-targeted analytical strategies," Food and Function, vol. 3, pp. 976-984, 2012.

[149] W. Lei, Z. Pengyue, Z. Fengzu, B. Aijuan, and P. Canping, "Detection of caffeine in tea, instant coffee, green tea beverage, and soft drink by direct analysis in real time (DART) source coupled to single-quadrupole mass spectrometry," Journal of AOAC International, vol. 96, no. 2, pp. 353-356, 2013.

[150] R. Hertz-Schünemann, T. Streibel, S. Ehlert, and R. Zimmermann, "Looking into individual coffee beans during the roasting process: direct micro-probe sampling online photo-ionisation mass spectrometric analysis of coffee roasting gases," Analytical and Bioanalytical Chemistry, vol. 405, no. 22, pp. 7083-7096, 2013.

[151] J. S. Ribeiro, M. M. C. Ferreira, and T. J. G. Salva, "Chemometric models for the quantitative descriptive sensory analysis of Arabica coffee beverages using near infrared spectroscopy," Talanta, vol. 83, no. 5, pp. 1352-1358, 2011.

[152] X. Zhang, W. Li, B. Yin et al., "Improvement of near infrared spectroscopic (NIRS) analysis of caffeine in roasted Arabica coffee by variable selection method of stability competitive adaptive reweighted sampling (SCARS)," Spectrochimica Acta A, vol. 114, pp. 350-356, 2013.

[153] R. Consonni, L. R. Cagliani, and C. Cogliati, "NMR based geographical characterization of roasted coffee," Talanta, vol. 88, pp. 420-426, 2012.

[154] N. D’Amelio, L. Fontanive, F. Uggeri, F. Suggi-Liverani, and L. Navarini, "NMR reinvestigation of the caffeine-chlorogenate complex in aqueous solution and in coffee brews," Food Biophysics, vol. 4, no. 4, pp. 321-330, 2009. 
[155] F. Wei, K. Furihata, F. Hu, T. Miyakawa, and M. Tanokura, "Complex mixture analysis of organic compounds in green coffee bean extract by two-dimensional NMR spectroscopy," Magnetic Resonance in Chemistry, vol. 48, no. 11, pp. 857-865, 2010.

[156] G. del Campo, I. Berregi, R. Caracena, and J. Zuriarrain, "Quantitative determination of caffeine, formic acid, trigonelline and 5-(hydroxymethyl)furfural in soluble coffees by $1 \mathrm{H}$ NMR spectrometry," Talanta, vol. 81, no. 1-2, pp. 367-371, 2010. 


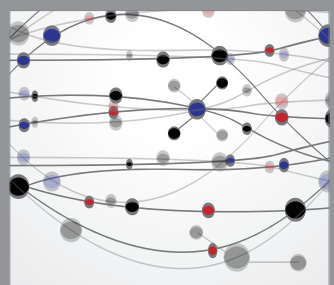

The Scientific World Journal
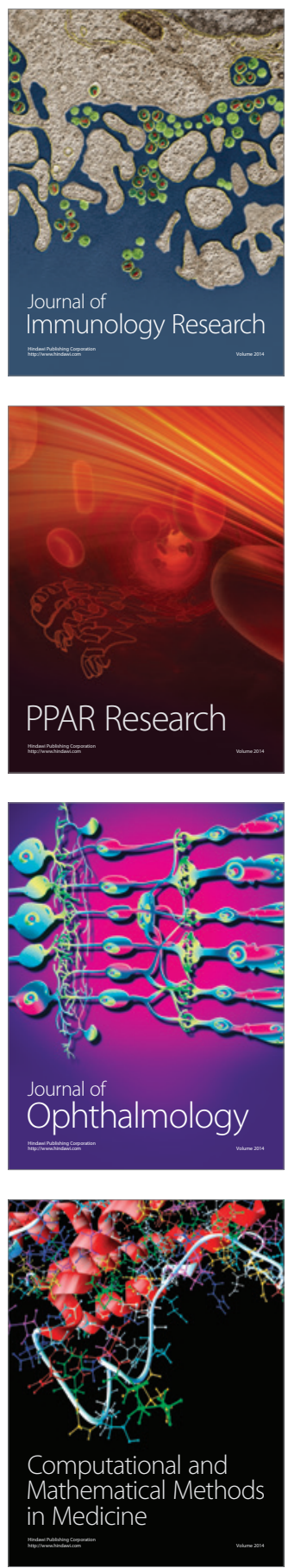

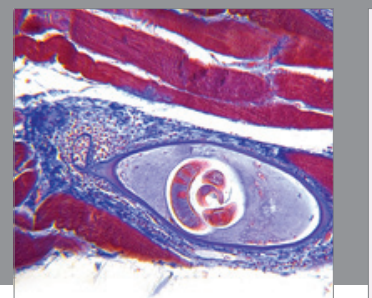

Gastroenterology

Research and Practice
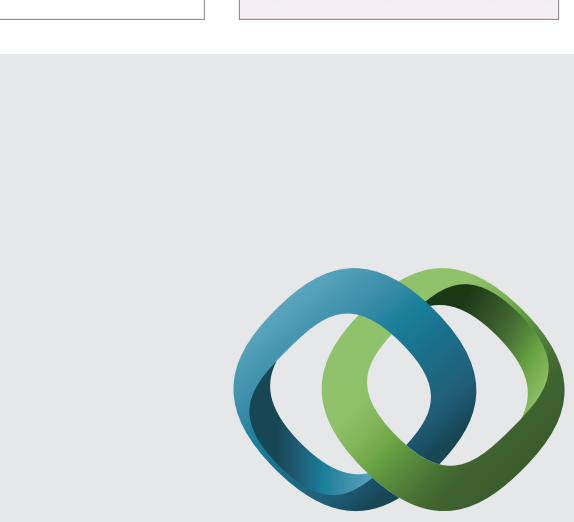

\section{Hindawi}

Submit your manuscripts at

http://www.hindawi.com
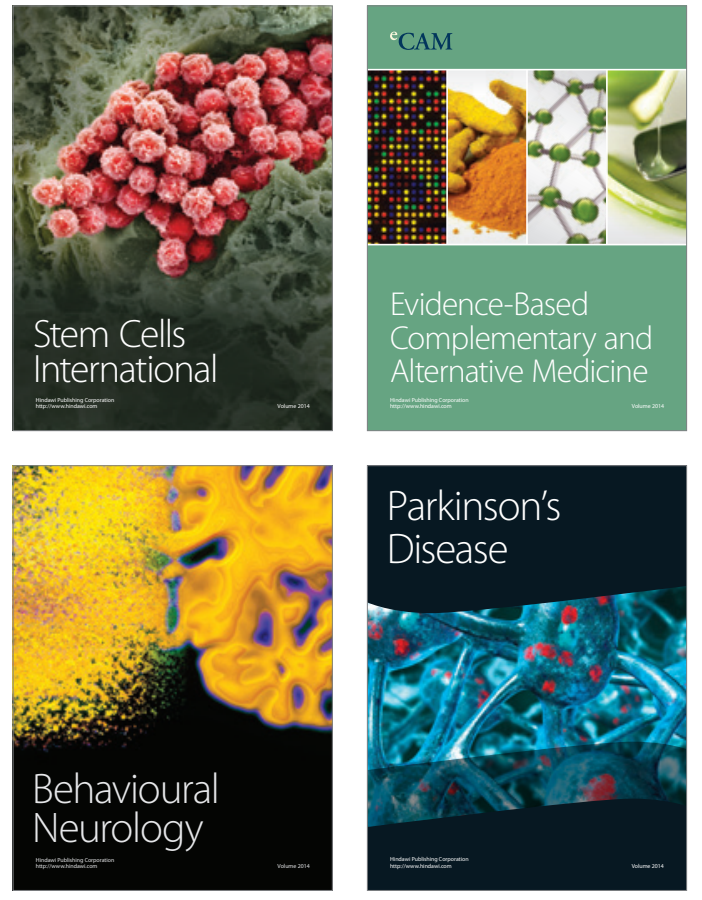
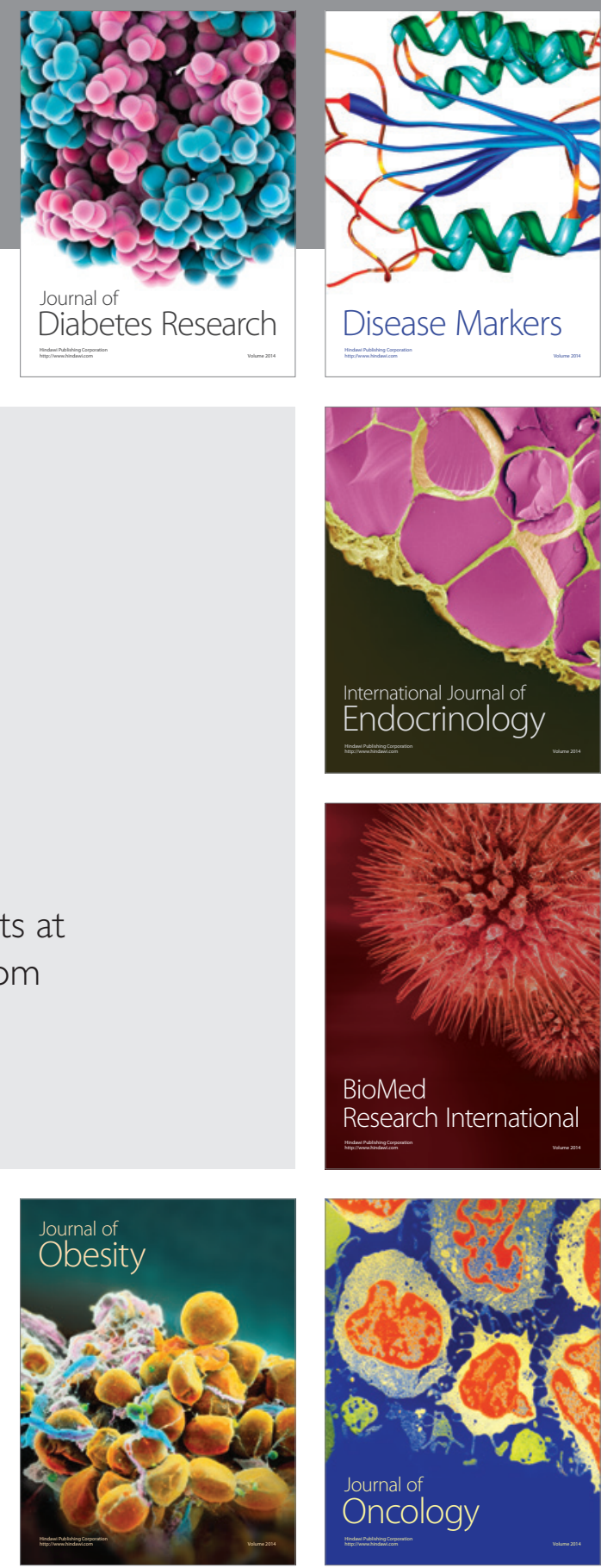

Disease Markers
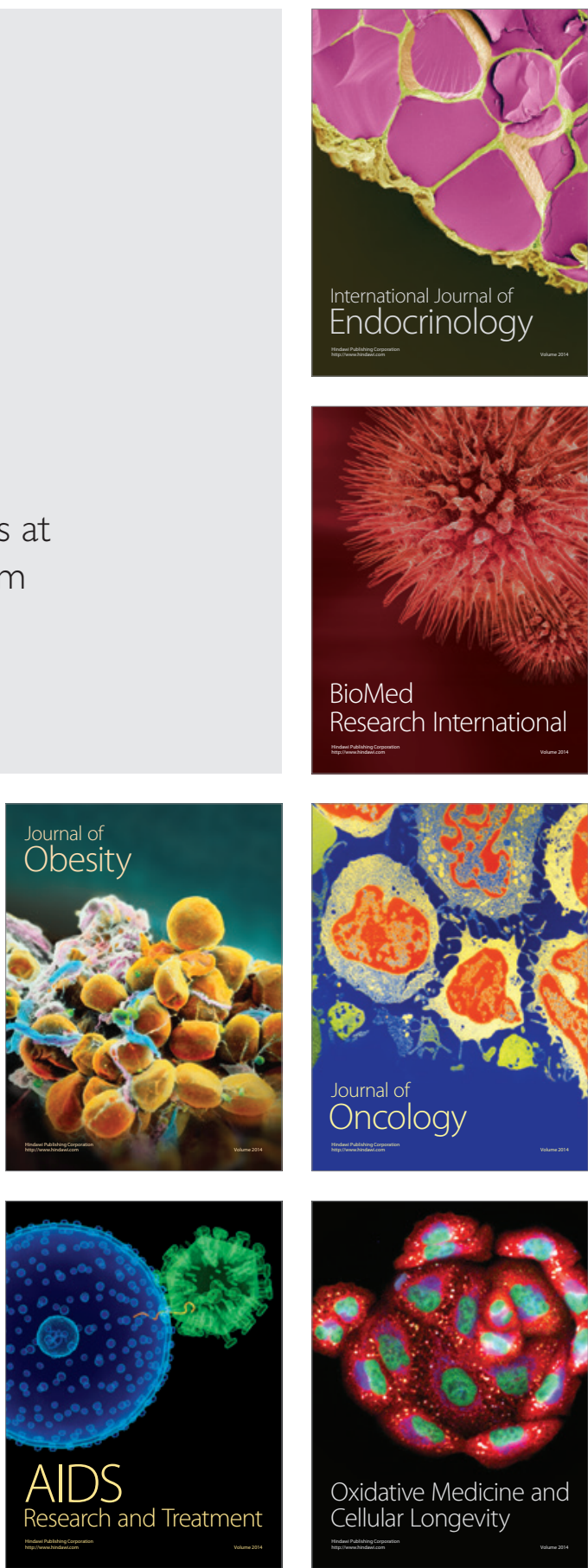